mineralogical, and geological collections were confiscated by the Japanese authorities in 1828 ; fortunately, not long before he had sent many specimens to Leyden. He also sent a living tea plant to Java, thus originating tea culture on that island. In 1827, Siebold published a small catalogue of Japanese economic plants. On Dec. 30, 1829, political unrest was so acute that he was ordered to leave Japan, and he then settled in Holland. He met the German singer, J. J. Hoffmann, who was also a linguist. In 1845, Hoffmann published a description of Siebold's books, manuscripts, and maps which he had brought from Japan. Zuccarini, the Munich botanist, helped with the classification of botanical material. Publication of the "Flora Japonica " was begun in 1835 and continued until 1842, but after Zuccarini's death, von Siebold discontinued further publication and the materials became the property of the Government Herbarium at Leyden, where the Von Siebold Collection is still visited and consulted by botanists. Von Siebold's influence on horticulture was even greater. His imported specimens formed a nucleus for horticulture in Belgium and Holland, but the original "Jardin d'Acclimatisation: Nippon" no longer exists. His zoological collections are preserved in the Museum of Natural History at Leyden and his ethnographical material at the Leyden Ethnographical Museum. Von Siebold died at Munich on Oct. 18, 1866.

\section{Decline of Australian Parrakeets}

THE re-discovery of a species supposed to have become extinct is especially a matter of congratulation when it has some particular claim to interest, as is the case with the splendid grass-parrakeet (Neophema splendida), of which a pair has recently reached England as a present to H.M. The King. Mr. D. Seth-Smith, in commenting on this in the Avicultural Magazine for January (p. 36), mentions that a few captured specimens had appeared in Adelaide, and that, always rare, the species, which is found in south and south-western Australia, had completely disappeared for about sixty years, and was supposed to be extinct, until a specimen occurred at Koonibha, crippled by collision with a wire fence. The special interest of the species lies in the very brilliant colouring of the male, which has a blue face and wing-patches, a scarlet breast, and yellow abdomen, contrasting with the green of the upper surface; the female has no red and is generally duller. The length is about eight inches. A whole group of small grass-seed-eating Australian parrakeets like this appears to be on the decline, common species like the turquoisine (N.pulchella) suffering as well as this rare one. Fortunately, like so many Australian birds, they are free breeders in captivity, and may possibly be preserved if domesticated as the budgerigar has been.

\section{False Mimicry in Animals}

THE short-tailed South American monkeys known as uakaris are never common in captivity, so it is as well to direct attention to the recent acquisition of a specimen of the red uakari (Cacajao rubicundus) by the Zoological Society of London, which exhibits it in the Tropical House along with some more familiar American monkeys. The resemblance of this species to an orang-utan in miniature is noticeable, and is paralleled in the Bird House next door by a specimen of the South American magpie tanager (Cissopis leveriana), which exhibits an equally striking resemblance in miniature to the magpie. Other more striking examples could be given, in both mammals and birds, of this false mimicry, or resemblance between creatures which do not inhabit the same region, when size as well as general appearance correspond. In the Bird House may also be seen an example of Chaulet's Cissa (Cissa hypoleuca Chauleti), which will be interesting to watch, as, like the better-known Indian species $(C$. sinensis $)$, this green bird changes into blue without a moult, the change taking place by a gradual alteration of tint, which reminds one of the fading into blue of green paint.

\section{A Direct Reading Optical Micrometer}

A Microscope for measuring small lengths has recently been put on the market by Messrs. W. Ottway and Co., Ltd., Orion Works, Ealing, W.5. The microscope, which gives a magnification of 25, is about $6.5 \mathrm{~cm}$. long and is mounted on a small tripod. Focusing is effected by sliding the microscope tube through the holder, fine adjustment being made by rotating a milled ring on the stand. Measurements are obtained by a direct reading of a scale on a graticule fitted into the microscope, a screw focusing adjustment being provided to bring the graticule into the focal plane of the eyepiece. Scales reading to 0.01 in. or 0.001 in. are supplied and are easily interchangeable. The instrument can conveniently be used as a linen counter, or for the measurement of Brinell impressions or of small objects up to $0 \cdot 1$ in. in length. For measurements of length up to $10 \mathrm{~mm}$. an alternative objective, fitted with a $0 \cdot 1 \mathrm{~mm}$. scale and giving a magnification of 15 , is obtainable. As the graticules may be ruled to any desired scale or pattern, the micrometer should prove useful as a test instrument in many industrial operations. It can easily be applied, for example, to the testing of screw threads, a graticule with the required thread form being used. Its compactness and the ease and speed with which readings may be made are additional advantages.

\section{Performance of Gears}

In a paper by Messrs. Hyde, Tomlinson, and Allan, of the National Physical Laboratory, read before the Institution of Automobile Engineers on April 4, an interesting account was given of researches which have been in progress at the Laboratory during the past few years on the performance of gears. The best gears are made of special alloy steels, either air or oil hardened, and afterwards finished to an accuracy of a few ten-thousandths of an inch by grinding. The work of the Laboratory shows that such gears can transmit power with the very high efficiency of more than 99 per cent. At the high speeds of rotation to which gears are subjected, a tooth out of its true position by less than a thousandth of an inch may come into mesh with a shock sufficient to double or

$$
\text { No. 3258, VoL. 129] }
$$

